\title{
THE TAGUCHI APPROACH IN OPTIMIZING ENVIRONMENTAL FACTORS AFFECTING PRODUCTIVITY IN THE AUTOMOTIVE INDUSTRY
}

\author{
M.H.M. Haniff ${ }^{1}$, A.R. Ismail ${ }^{2}$, B.M. Deros ${ }^{1}$, M.N.A. $\operatorname{Rahman}^{1}$ and K. Kardigama $^{2}$ \\ ${ }^{1}$ Department of Mechanical and Materials Engineering \\ Faculty of Engineering and Built Environment, Universiti Kebangsaan Malaysia \\ 43600 UKM, Bangi, Selangor, Malaysia \\ ${ }^{2}$ Faculty of Mechanical Engineering, Universiti Malaysia Pahang \\ 26600 UMP, Pekan, Pahang, Malaysia \\ E-mail: arasdan@gmail.com
}

\begin{abstract}
The objective of this study is to determine the dominance effects of environmental factors such as illuminance, humidity and WBGT on operators' productivity in the Malaysian automotive industry. A case study was carried out at an automotive components assembly factory. The environmental factors examined were the illuminance (lux), humidity and WBGT of the surrounding workstation area. Two sets of representative data including the illuminance, humidity and WBGT level and production rate were collected during the study. The production rate data were collected through observations and survey questionnaires while the illuminance level was measured using photometer model RS 180-7133, and the humidity and WBGT level were measured by using Quest Temp apparatus and humidity. The Taguchi method was utilized to find the sequence of dominant factors that contributed to the productivity of the operator at that specified production workstation. The study reveals that the dominant factor that contributed to the productivity was humidity, followed by illuminance and WBGT.
\end{abstract}

Keywords: Productivity, illuminance, humidity, WBGT.

\section{INTRODUCTION}

The automotive industry plays an important economic role, and in Malaysia it is a booming industry which encompasses number of related areas of activity (Yazdani et al., 2009). Over the years, car production has also been increasing: in 1999 almost 254,000 cars were produced but this had doubled (442,000 cars) by 2007 and was employing 47,000 workers in Malaysia (IOMVM, 2007). Robust design is an engineering methodology for obtaining product and process conditions which are minimally sensitive to the various causes of variation, to produce high-quality products with low development and manufacturing costs (Park, 1996). Taguchi's parameter design is an important tool for robust design. It offers a simple and systematic approach to optimize design for performance, quality and cost. Two major tools used in robust design (Park, 1996; Unal \& Dean, 1991; Phadke, 1989) are:

- Signal to noise ratio, which measures quality with emphasis on variation, and

- Orthogonal arrays, which accommodate many design factors simultaneously.

Taguchi's approach is totally based on statistical design of experiments (Park, 1996), and this can economically satisfy the needs of problem solving and product or 
process design optimization. By applying this technique one can significantly reduce the time required for experimental investigation, as it is effective in investigating the effects of multiple factors on performance as well as studying the influence of individual factors to determine which factor has more influence, and which less (Park, 1996). Some of the previous works that used the Taguchi method as a tool for the design of experiments in various areas including metal cutting are listed in the references (Yang \& Tarng, 1998; Lin, 2002; Tsui, 1999; Zhang \& Wang, 1998; Si \& Tong, 1997; Kopac et al., 2002).

The most important stage in the design of an experiment lies in the selection of control factors. As many factors as possible should be included, so that it is possible to identify non-significant variables at the earliest opportunity. Taguchi creates a standard orthogonal array to accommodate this requirement. Depending on the number of factors, interactions and levels needed, the choice is left to the user to select either the standard or column-merging method or idle-column method, etc. Two of the applications in which the concept of $\mathrm{S} / \mathrm{N}$ ratio is useful are the improvement of quality through variability reduction and the improvement of measurement. The $\mathrm{S} / \mathrm{N}$ ratio characteristics can be divided into three categories when the characteristic is continuous (Park, 1996):

Nominal is the best characteristic:

$$
\frac{s}{N_{L B}}=10 \log \left(\frac{y}{s_{y}^{2}}\right)
$$

The smaller the better characteristics:

$$
\frac{s}{N_{L B}}=-10 \log \left(\frac{1}{n} \sum_{i=1}^{n} y_{i}^{2}\right)
$$

The larger the better characteristics:

$$
\frac{s}{N_{L B}}=-10 \log \left(\frac{1}{n} \sum_{i=1}^{n} \frac{1}{y_{i}^{2}}\right)
$$

where $\bar{y}$ is the average of observed data, $\mathrm{s}_{\mathrm{y}}{ }^{2}$ is variance of $y, n$ is number of observations, and $y$ is the observed data. For each type of characteristic, with the above $\mathrm{S} / \mathrm{N}$ ratio transformation, the higher the $\mathrm{S} / \mathrm{N}$ ratio, the better the result is.

A study of office workers at a call centre by Boyce (2004) indicated that illuminance has a statistically significant effect on average handling time, that is, greater than $1 \%$. The biggest effect of these variables predicted by the regression is between $17 \%$ and $19 \%$ reduction in average handling time. Staffan and Knez (2001) investigated how noise, air temperature, and illuminance combine or interact in their effects on cognitive performance. The results of their study showed that the subjects worked faster in noise but at the cost of lesser accuracy. Interactions were found between noise and heat on the long-term recall of a text, and between noise and light on the free recall of emotionally toned words. In the metal industry, Van Bommel et al. (2002) conducted a study on the effect of increasing the illuminance based on increased task performance, reduction of rejects and the decreased number of accidents. The result of the study revealed that increasing the illuminance from the minimum 300 lux required to 500 lux 
could lead to an increase in productivity of between $3 \%$ and $11 \%$, based on which realistic assumptions were made that an increase of illuminance from 300 lux to 2000 lux would increase productivity by between $15 \%$ and $20 \%$ (Bommel et al., 2002). Juslen and Tenner (2005) described the mechanisms involved in enhancing human performance by changing the lighting in the industrial workplace through visual performance, visual comfort, visual ambience, interpersonal relationships, biological clock, stimulation, job satisfaction, problem solving, the halo effect, and the change process.

Improving workers' productivity, occupational health and safety are major concerns of industry, especially in developing countries. However, these industries feature improper workplace design, ill-structured jobs, a mismatch between workers' abilities and job demands, adverse environment, poor human-machine system design and inappropriate management programs (Shikdar \& Sawaqed, 2003). Light, noise, air quality and the thermal environment were considered factors that would influence the acceptability and performance of the occupants of premises (Olesen, 1995). Dua (1994) stated that lower emotional health is manifested as psychological distress, depression and anxiety, whereas lower physical health is manifested as heart disease, insomnia, headaches, and infections. These health problems could lead to organizational symptoms such as job dissatisfaction, absenteeism, and poor work quality. Irritated, sore eyes and throat, hoarseness, stuffy congested nose, excessive mental fatigue, headaches and unusual tiredness were all signs of negative workplace environmental conditions (Tarcan et al., 2004).

According to Fisk and Rosenfeld (1997), productivity is one of the most important factors affecting the overall performance of any organization, from small enterprises to entire nations. Increased attention has focused on the work environment and productivity since the 1990s. Laboratory and field studies showed that the physical and chemical factors in the work environment could have a notable impact on the health and performance of the occupants, and consequently on productivity. Workplace environmental conditions, such as humidity, indoor air quality, and acoustics have significant relationships with workers' satisfaction and performance (Tarcan et al., 2004; Marshall et al., 2002; Fisk, 2000). Indoor air quality could have a direct impact on health problems and leads to uncomfortable workplace environments (Juslen \& Tenner, 2005; Fisk \& Rosenfeld, 1997; Marshall et al., 2002).

Previous research by Ettner and Grzywacz (2001) showed that work environments were associated with the perceived effects of work on health. This research used a national sample of 2,048 workers who were asked to rate the impact of their respective jobs on their physical and mental health. Regression analyses proved that the workers' responses were significantly correlated with health outcomes. In addition to this, Shikdar and Sawaqed (2003) pointed out that there was high correlation between performance indicators and health, facilities, and environmental attributes. In other words, companies with greater health, facilities, and environmental problems could face more performance-related problems such as low productivity, and high absenteeism. Employees with complaints of discomfort and dissatisfaction at work could have their productivity affected, as a result of their inability to perform their work properly (Leaman, 1995). 


\section{METHODOLOGY}

\section{Selection of Location and Subjects}

The study is conducted on a selected work station in the automotive industry and refers mainly towards the assembly section or the manual production line, where human energy is involved in the manufacturing activity. Figure 1 shows the production line layout.

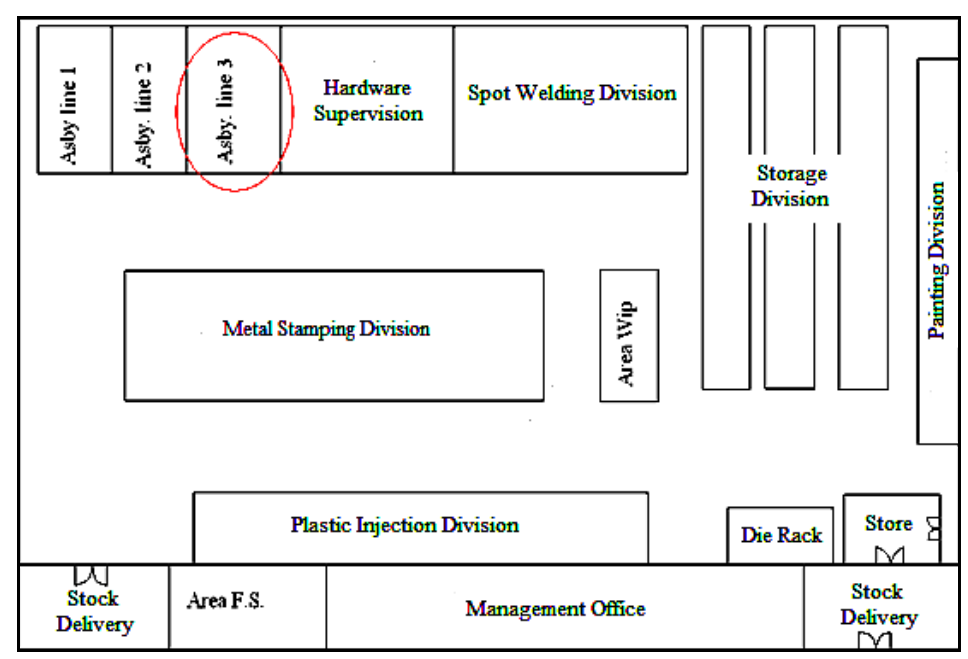

Figure 1. Door check production line

The work requires the repeated production of the same component throughout the entire shift; this is to ensure the consistency of the data collected towards the data analysis later. Priority in the study is given to the work station where the environmental factors have the greatest effect on the productivity. One automotive vendor was selected as a place of study. A line producing a product over a period of time and under the effects of a certain relative humidity, illuminance and wet bulb globe temperature (WBGT) was chosen. Figure 2 shows the flow chart of work sequences on the production line. This criterion is essential in order to identify which factors contribute the most to worker productivity, which is based on the output of assemblies among operators. The production line consisted of 10 female operators. The task is to assemble an automotive part which is known as the door check. The standard production rate, as determined by the previous feasibility study, to assemble a complete door check was 240 units for every hour of production.

\section{Experimental Method}

The Taguchi design of experiment was employed in this experiment with two factors at two levels each. The fractional factorial design used was a standard $\mathrm{L}_{8}$ orthogonal array (Park, 1996). This orthogonal array was chosen because of its minimum number of experimental trials. Each row of the matrix represented one trial. However, the sequence in which these trials were carried out was random. The factors and levels identified in this study are shown in Table 1. 


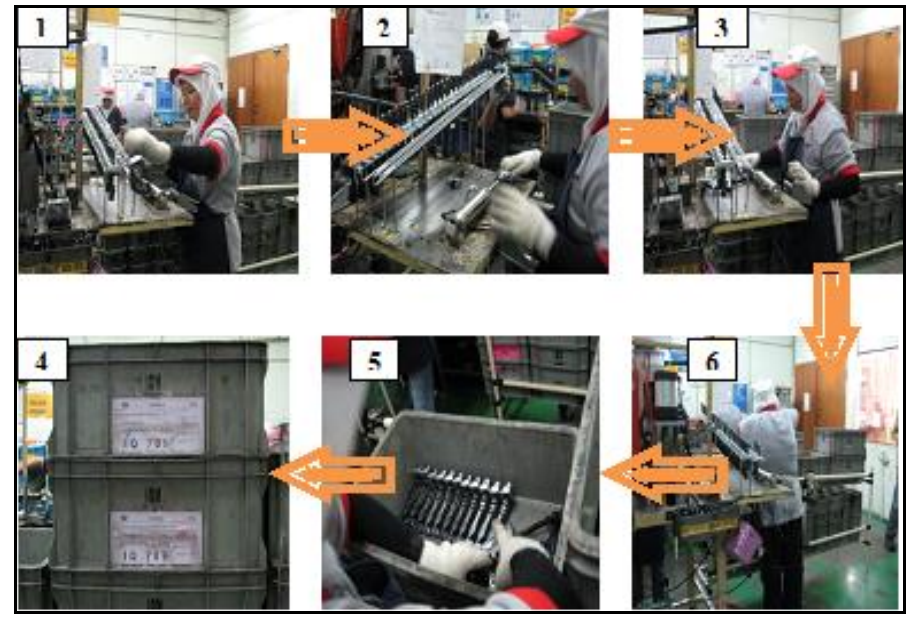

Figure 2. The works sequence to assemble a complete door check

Table 1. Factors and levels used in the experiment

\begin{tabular}{ccccc}
\hline Symbol & Factors & Unit & Level 1 & Level 2 \\
\hline A & Illuminance & lux & $<500$ & $>500$ \\
B & Relative Humidity & $(\%)$ & $<60$ & $>60$ \\
C & WBGT & ${ }^{\circ} \mathrm{C}$ & $<23$ & $>23$ \\
\hline
\end{tabular}

\section{Orthogonal Array Experiments}

To select an appropriate orthogonal array for experiments, the total degree of freedom needs to be determined. The degree of freedom is defined as the number of comparisons between factors that are needed to determine which level is better and specifically how much better. In the present study, since each factor has two levels, there are therefore three degrees of freedom. In this study an $\mathrm{L}_{8}$ orthogonal array is used, as shown in Table 2.

Table 2. Experimental layout using an $\mathrm{L}_{8}$ orthogonal array

\begin{tabular}{cccc}
\hline & \multicolumn{3}{c}{ Factor levels } \\
\cline { 2 - 4 } & $\mathrm{A}$ & $\mathrm{B}$ & $\mathrm{C}$ \\
\hline Experiment number & Illuminance & Relative Humidity & WBGT \\
\hline 1 & 1 & 1 & 1 \\
2 & 1 & 1 & 2 \\
3 & 1 & 2 & 1 \\
4 & 1 & 2 & 2 \\
5 & 2 & 1 & 1 \\
6 & 2 & 1 & 2 \\
7 & 2 & 2 & 1 \\
8 & 2 & 2 & 2 \\
\hline
\end{tabular}




\section{RESULTS AND DISCUSSION}

The results of this study are based on the case study conducted on the production line in the automotive vendor factory. The hypothesis for this study was that the production rate has a direct relationship with illuminance, humidity and WBGT level. The levels of illuminance, humidity and WBGT were measured to identify their effect on the workers' performance. Table 3 shows the data on the production rate, illuminance, WBGT and humidity level collected during the experimental period at 30 minute intervals.

Table 3. Data on the illuminance level, humidity and WBGT, productivity and period

\begin{tabular}{|c|c|c|c|c|c|}
\hline Time & $\begin{array}{c}\text { Production } \\
\text { Target (units) }\end{array}$ & $\begin{array}{l}\text { Production } \\
\text { Rate (units) }\end{array}$ & $\begin{array}{c}\text { Illuminance } \\
(\text { lux })\end{array}$ & $\begin{array}{c}\text { Relative } \\
\text { Humidity } \\
(\%)\end{array}$ & $\begin{array}{c}\text { WBGT } \\
\left({ }^{\circ} \mathbf{C}\right)\end{array}$ \\
\hline $\begin{array}{c}09.05- \\
09.35\end{array}$ & 120 & 119 & 497.65 & 60.76 & 22.98 \\
\hline $\begin{array}{c}09.35- \\
10.05\end{array}$ & 120 & 123 & 505.20 & 59.85 & 23.19 \\
\hline $\begin{array}{c}10.05- \\
10.35\end{array}$ & 120 & 121 & 504.65 & 59.21 & 23.13 \\
\hline $\begin{array}{c}10.35- \\
11.05\end{array}$ & 120 & 115 & 503.95 & 59.55 & 23.25 \\
\hline $\begin{array}{c}11.05- \\
11.35\end{array}$ & 120 & 121 & 503.83 & 59.29 & 23.15 \\
\hline $\begin{array}{c}12.05- \\
12.35\end{array}$ & 120 & 124 & 501.16 & 59.61 & 22.86 \\
\hline $\begin{array}{c}12.35- \\
01.05\end{array}$ & 120 & 108 & 492.45 & 55.98 & 23.25 \\
\hline $\begin{array}{c}02.10- \\
02.40\end{array}$ & 120 & 112 & 489.89 & 55.84 & 23.82 \\
\hline $\begin{array}{c}02.40- \\
03.10\end{array}$ & 120 & 106 & 479.50 & 55.45 & 24.06 \\
\hline
\end{tabular}

The objective of the experiment is to optimize the environmental parameters (WBGT, illuminance and humidity) in order to obtain a better production rate (high value) and therefore the optimum characteristics of the environment should be quantified.

\section{Linear Relation Analysis}

Based on the graph in Figure 3, the production rate was improved with the increase of the illuminance (lux). The results obtained for the illuminance are in line with the findings of Van Bommel et al. (2002) and Juslen and Tenner (2005) that increasing the illuminance levels leads to an increase in productivity. A different trend is observed for the relative humidity (\%) and the productivity, as shown in Figure 4. 


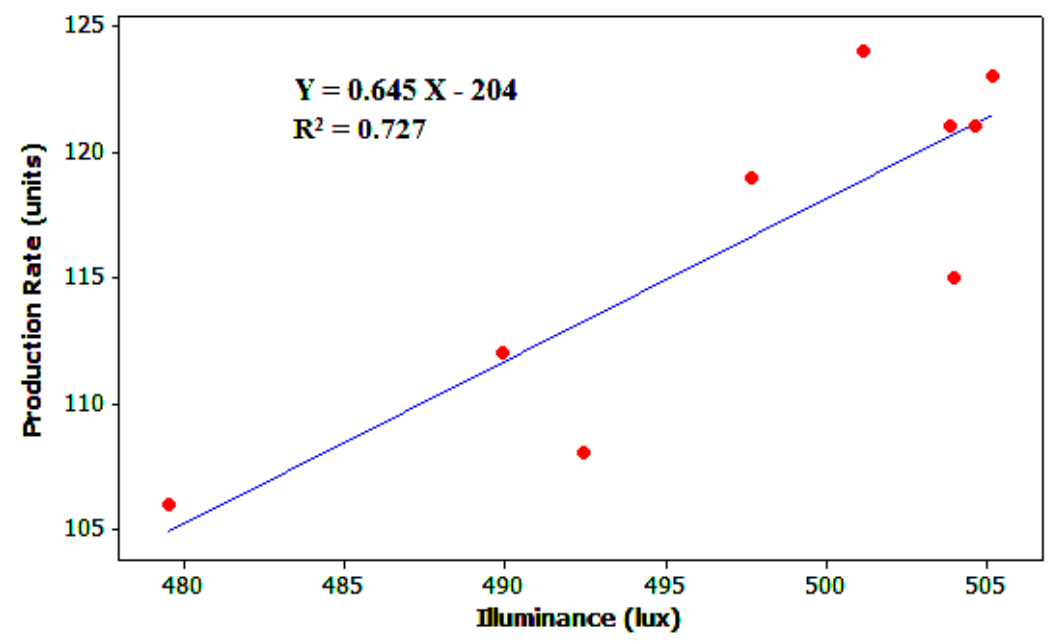

Figure 3. Production rate versus illuminance level

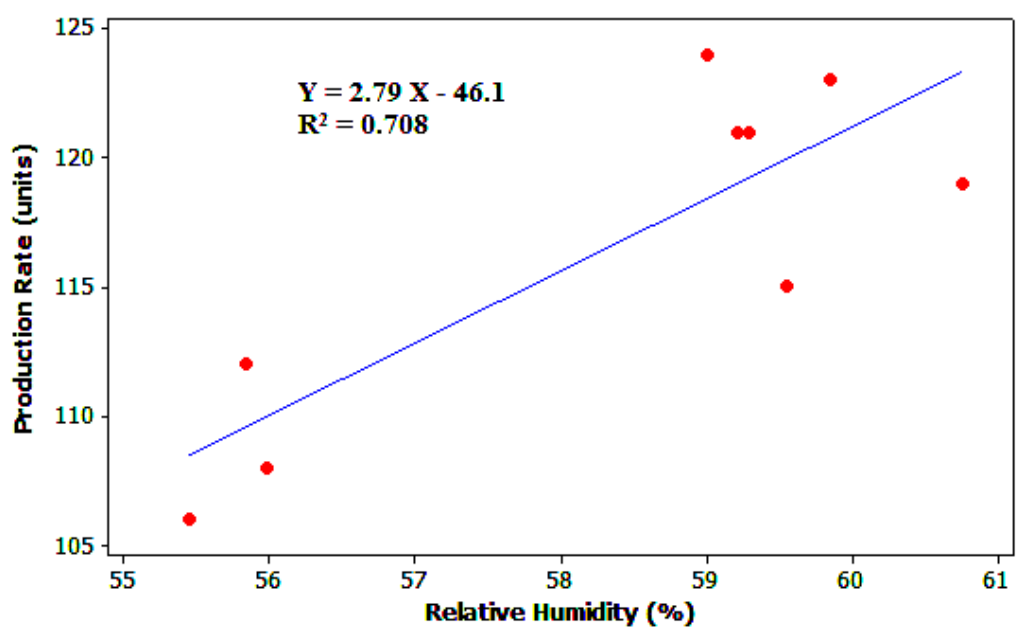

Figure 4. Production rate versus relative humidity

The finding on the effect of relative humidity on productivity is in line with the findings of Tsutsumi et al. (2007), who found that the subjective performance was at the same level at four different levels of relative humidity. However, Tsutsumi et al. (2007) reported that their subjects were more tired at $70 \% \mathrm{RH}$ after a relative humidity (\%) step change.

The trend obtained for the relation of illuminance and relative humidity and productivity is different from the relation of Wet Bulb Globe Temperature (WBGT) and productivity. Fig. 5 shows that increasing the WBGT will reduce the performance and productivity of the operators. Our findings for WBGT were similar to those of Fisk and Rosenfeld (1997) that increasing the air ventilation will significantly increase the performance of the operators. The productivity increase caused by the WBGT could be related to the attention and cognitive aspect of the operators, which has been studied by Staffan and Knez (2001). They found that the combination of air temperature and illuminance level had a significant effect on cognitive performance. 


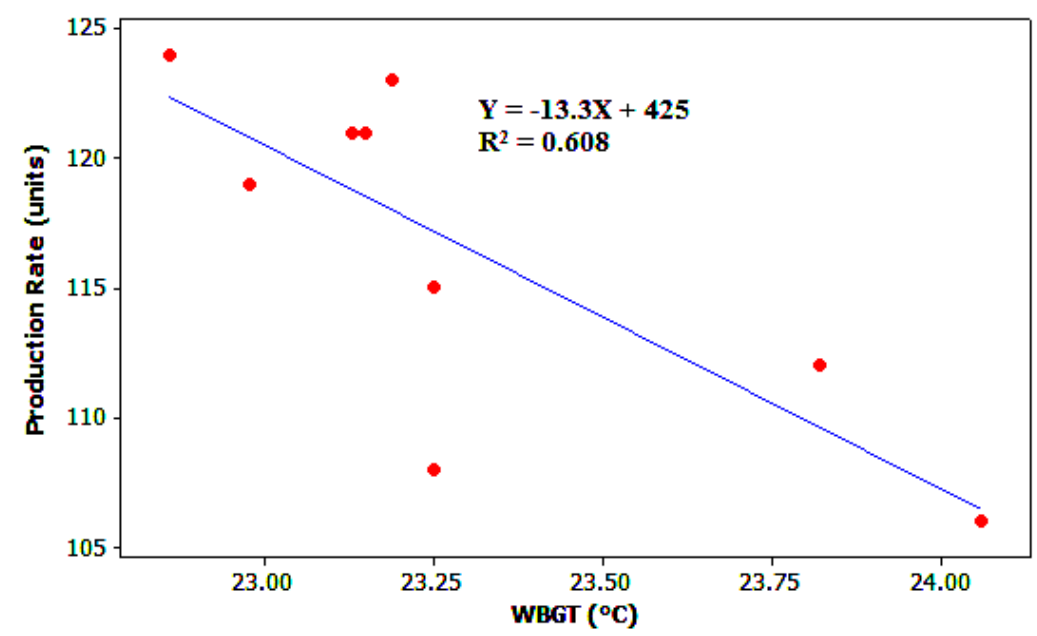

Figure 5. Production rate versus WBGT

\section{Taguchi Approach}

Taguchi recommends analysing the means and $\mathrm{S} / \mathrm{N}$ ratio using a conceptual approach that involves graphing the effects and visually identifying the factors that appear to be significant, without using ANOVA, thus making the analysis simple (Park, 1996). The $\mathrm{S} / \mathrm{N}$ ratio graph for the production rate, indicating the bigger the ratio the better, is shown in Figure 6. It shows that relative humidity is the most significant factor in controlling the production rate, followed by illuminance and WBGT. Figure 6 also shows that the optimum conditions for the production rate are at level 1 (less than $60 \%$ ) of humidity, level 1 (less than 500 Lux) of illuminance and level 2 of WBGT (more than $23^{\circ} \mathrm{C}$ ). The $\mathrm{L}_{8}$ orthogonal array for the environment parameters and production rate is shown in Table 4.

Table 4. Experimental result for productivity and $\mathrm{S} / \mathrm{N}$ ratio

\begin{tabular}{|c|c|c|c|c|c|}
\hline $\begin{array}{c}\text { Experiment } \\
\text { number }\end{array}$ & $\begin{array}{c}\mathbf{A} \\
\text { Illuminance } \\
(\operatorname{lux})\end{array}$ & $\begin{array}{c}\text { B } \\
\text { Relative } \\
\text { Humidity } \\
(\%)\end{array}$ & $\begin{array}{c}\text { C } \\
\text { WBGT } \\
\left({ }^{\circ} \mathrm{C}\right) \\
\end{array}$ & $\begin{array}{c}\text { Production } \\
\text { Rate } \\
\text { (units) } \\
\end{array}$ & $\begin{array}{c}\text { S/N } \\
\text { Ratio } \\
\text { dB }\end{array}$ \\
\hline 1 & $<500$ & $<60$ & $<23$ & 119 & 41.51 \\
\hline 2 & $<500$ & $<60$ & $>23$ & 123 & 41.80 \\
\hline 3 & $<500$ & $>60$ & $<23$ & 121 & 41.66 \\
\hline 4 & $<500$ & $>60$ & $>23$ & 115 & 41.21 \\
\hline 5 & $>500$ & $<60$ & $<23$ & 121 & 41.66 \\
\hline 6 & $>500$ & $<60$ & $>23$ & 124 & 41.87 \\
\hline 7 & $>500$ & $>60$ & $<23$ & 108 & 40.67 \\
\hline 8 & $>500$ & $>60$ & $>23$ & 112 & 40.98 \\
\hline
\end{tabular}

Table 5 shows the mean $\mathrm{S} / \mathrm{N}$ ratio for each factor at two levels. From this table, the highest value for each mean $\mathrm{S} / \mathrm{N}$ ratio for each factor can be identified clearly. For illuminance, the level 1 of $<500$ lux gives the highest value; for relative humidity, the 
level 1 of $<60 \%$ gives the highest value and for WBGT, the level 2 of $>23^{\circ} \mathrm{C}$ gives the highest value. Figure 6 shows the $\mathrm{S} / \mathrm{N}$ graph for the experimental results.

Table 5. Response table for signal to noise ratios (larger is better)

\begin{tabular}{ccccc}
\hline Symbol & Factors & \multicolumn{3}{c}{ Mean S/N ratio (dB) } \\
\cline { 3 - 5 } & & Level 1 & Level 2 & Rank \\
\hline A & Illuminance & 41.54 & 41.29 & 2 \\
B & Relative Humidity & 41.71 & 41.13 & 1 \\
C & WBGT & 0.58 & 41.47 & 3 \\
\hline
\end{tabular}

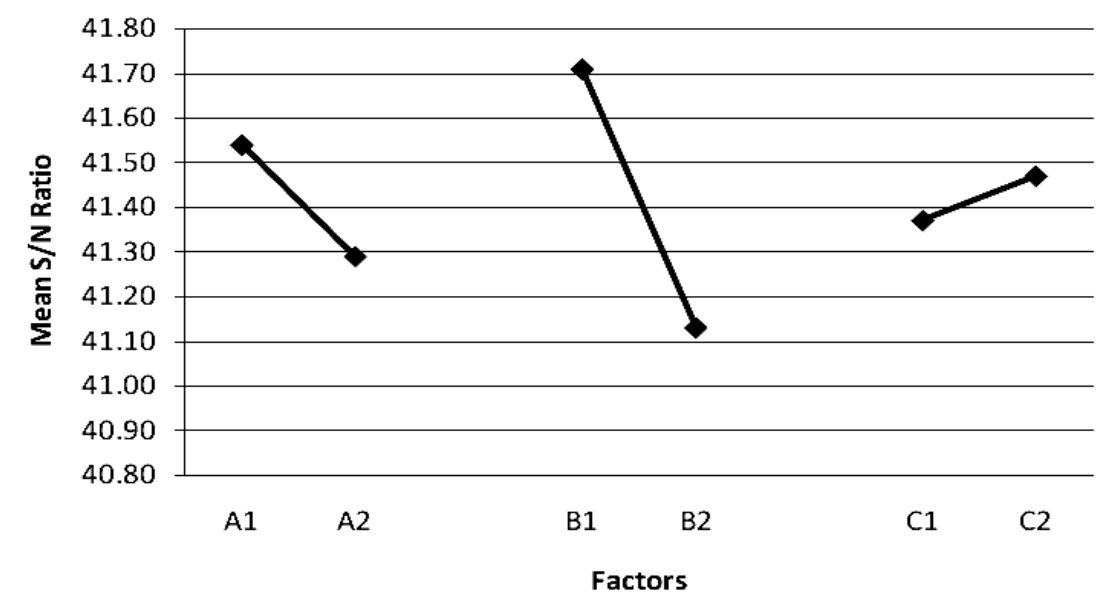

Figure 6. S/N graph for production rate

\section{Analysis of Variance (ANOVA)}

The purpose of ANOVA is to investigate which of the factors significantly affect the workers' productivity. Table 6 shows the results of analysis of variance. Statistically, the F-test can be used to determine which factors have a significant effect on the workers' productivity. The sequential sums of squares (Seq SS) measure the reduction in the residual sums of squares provided by each additional term in the model. The adjusted sums of squares (Adj SS) measure the reduction in the residual sums of squares provided by each term relative to a model containing all the other terms. The $\mathrm{F}$ value for each factor is then a ratio of the MS to the mean square of error. The larger the $\mathrm{F}$ value, the greater the effect on the performance characteristics (productivity of workers) due to the change of operating factors. Usually, when F>4 it means that the change of operating factors has a significant effect on the quality characteristics.

From the results of the ANOVA presented in Table 6, it can be seen that only relative humidity is statistically significant. However, each factor contributes to the quality characteristics and the rank order is relative humidity (rank 1), illuminance (rank 2) and WBGT (rank 3) respectively. Therefore, based on the S/N ratio and ANOVA analysis, the optimal parameters for achieving optimum productivity in terms of environmental factors are relative humidity at level $1(<60 \%)$, illuminance at level 1 $(<500$ lux $)$ and WBGT at level $2\left(>23^{\circ} \mathrm{C}\right)$. 
Table 6. Analysis of variance for $\mathrm{S} / \mathrm{N}$ ratios

\begin{tabular}{clcccccc}
\hline Symbol & Factors & DF & Seq SS & Adj SS & Adj MS & F & P \\
\hline A & Illuminance & 1 & 0.125 & 0.125 & 0.125 & 1.11 & 0.351 \\
B & Relative Humidity & 1 & 0.667 & 0.667 & 0.667 & 5.93 & 0.042 \\
C & WBGT & 1 & 0.017 & 0.017 & 0.017 & 0.16 & 0.714 \\
Error & & 4 & 0.450 & 0.450 & 0.113 & & \\
Total & & 7 & 1.260 & & & & \\
\hline
\end{tabular}

From the literature, only a few studies have been conducted in the area to establish a dominant environmental parameter that contributes to worker productivity. The authors believe this study has achieved the objective of establishing the dominant environmental parameters that contribute to productivity. The findings of the current investigation correspond with the result of the study by Tsutsumi et al. (2007), who found that the subjective performance was at the same level under four different levels of relative humidity. However, Tsutsumi et al. (2007) reported that their subjects were more tired at $70 \% \mathrm{RH}$ after a relative humidity (\%) step change. This was also supported by Ismail et al. (2008), who found that relative humidity has a linear relationship with productivity. The two dominant factors identified in this study will provide a guideline to assist engineers to determine the relative humidity and illuminance level during feasibility studies to allow assembly production lines to achieve the optimum output.

The findings will also be useful to engineers in the design of humidity systems to improve the comfort of the work station area and control the productivity of workers. The dominant environmental parameter identified in this study is only applicable to the current condition of the selected assembly work station area in the Malaysian automotive industries. From the results of the study it can also be concluded that there is a relationship between illuminance, humidity and WBGT level with production rate. Therefore the findings from this study are in line with the previous studies that indicated that WBGT and illuminance play an important role in controlling the production rate because both factors contribute to the comfort level of the worker (Shikdar \& Sawaqed, 2003; Olesen, 1995; Dua, 1994).

\section{CONCLUSIONS}

Past research on modelling the relationship of workplace environmental factors with productivity or performance is very limited. In addition, it is characterised by a short time perspective, and not enough engineering data regarding the lead time, expected output capacity or perception, with an emphasis on survey methods, statistical analysis, satisfaction and preference measurement. This study was done to prove empirically the previous perception studies, based on the role of environmental factors in productivity. It is hoped that this study will be beneficial to the electronic manufacturing industries in Malaysia. The research findings are restricted to the Malaysian workplace environment, where awareness among workers on improving productivity is still low. The results might vary for tests carried out for different sample sizes, types of industries and countries. The study could be more extensive if the fraction of defects rate for the product is included in the analysis. Nevertheless, the authors believe that the modelling 
of the production rate as time series data is more than adequate to understand the effect of environmental factors on productivity.

\section{ACKNOWLEDGEMENT}

The authors would like to thank the National University of Malaysia and Ministry of Higher Education, Malaysia, for their support in providing a research grant for the project Modelling the Relationship of Thermal Comfort and Productivity in Malaysia's Energy Intensive Industries (UKM-GUP-TK-08-16-059).

\section{REFERENCES}

Bommel, J.W., Van Der Beld, G.J. and Ooyen, M.H.F. 2002. Industrial lighting and productivity. The Netherlands: Philips Lighting.

Boyce, P. 2004. Window and office: a study of office worker performance and the indoor environment. Technical Report. Lighting Research Centre, Rensselaer Polytechnic Institute.

Dua, J.K. 1994. Job stressors and their effects on physical health, emotional health, and job satisfaction in a university. Journal of Educational Administration, 32(1): 5978.

Ettner, S.L. and Grzywacz, J.G. 2001. Workers' perceptions of how jobs affect health: a social ecological perspective. Journal of Occupational Health Psychology, 6(2): 101-131.

Fisk, W.J. 2000. Health and productivity gains from better indoor environments and their relationship with building energy efficiency. Annual Review of Energy \& the Environment, 25(2): 537-566.

Fisk, W.J. and Rosenfeld, A.H. 1997. Estimates of improved productivity and health from better indoor environments. Indoor Air, 7: 158-172.

IOMVM (International Organization of Motor Vehicle Manufacturers). 2007. Production statistics.

Ismail, A.R., Rani, M.R.A., Makhbul, Z.K.M. and Deros, B.M. 2008. Relationship of relative humidity to productivity at a Malaysian electronics industry. Journal of Mechanical Engineering. 5(2): 63-72.

Juslen, H. and Tenner, A. (2005) Mechanisms involved in enhancing human performance by changing the lighting in the industrial workplace. International Journal of Industrial Ergonomics, 35(9): 843-855.

Kopac, J., Bahor, M. and Sokovic, M. .2002. Optimal machining parameters for achieving the desired surface roughness in fine turning of cold pre-formed steel work pieces. International Journal of Machine Tool and Manufacture, 42(6): 707716.

Leaman, A. 1995. Dissatisfaction and office productivity. Facilities, 13(2): 13-19.

Lin, T.R. 2002. Experimental design and performance analysis of TIN-coated carbide tool in face milling stainless steel. Journal of Material Processing Technology, 127(1): $1-7$.

Marshall, L., Weir, E., Abelsohn, A. and Sanborn, M.D. 2002. Identifying and managing adverse environmental health effects: 1. taking an exposure history. Canadian Medical Association Journal, 166(8): 1049-1055.

Olesen, B.W. (1995) International standards and the ergonomics of the thermal environment. Journal of Applied Ergonomics, 26, 293-302. 
Park, S.H. 1996. Robust design and analysis for quality engineering. Dordrecht Netherlands: Chapman and Hall.

Phadke, M.S. 1989. Quality engineering using robust design. New Jersey: Prentice Hall.

Shikdar, A.A. and Sawaqed, N.M. 2003. Worker productivity, and occupational health and safety issues in selected industries. Computers and Industrial Engineering, 45(4): 563-572.

$\mathrm{Si}$, C.T. and Tong, L.I. 1997. Multi response robust design by principal component analysis. Total Quality Management, 8(6): 409-416.

Staffan, H. and Knez, I. 2001. Effect of noise, heat, and indoor lighting on cognitive performance and self-reported affect. Journal of Environment Psychology, 21(3): 291-299.

Tarcan, E. Varol, E.S. and Ates, M.A. 2004. Qualitative study of facilities and their environmental performance management of environmental quality. Management of Environmental Quality: An International Journal, 15(2): 154-173.

Tsui, K.L. 1999. Modeling and analysis of dynamic robust design experiments. IEE Transactions, 31: 113-1122.

Tsutsumi, H., Tanabea, S.I., Harigayaa, J. I., Guchib, Y. and Nakamura, G. 2007. Effect of humidity on human comfort and productivity after step changes from warm and humid environment. Journal of Building and Environment, 42: 4034-4042.

Unal, R. and Dean, E.B. 1991. Taguchi approach to design optimization for quality and cost: an overview. Proceedings of the International Society of Parametric Analysts, pp. 21-24.

Van Bommel, W.J.M., Van Den Beld, G.J. and Van Ooyen, M.H.F. 2002. Industrial lighting and productivity. Technical Report from Philips. The Netherlands, August 2002.

Yang, W.H. and Tarng, Y.S. 1998. Design optimisation of cutting parameters for turning operations based on the Taguchi method. Journal of Material Processing Technology, 84: 122-129.

Yazdani, A., Anita, A.R., Hayati, K.S. and Adun, M.Y. 2009. Association between awkward posture and musculoskeletal symptom among automobile assembly line workers in Malaysia. Proceedings of the National Symposium on Advancements in Ergonomics and Safety (ERGOSYM), pp. 28-32.

Zhang, C. and Wang, H.P. 1998. Robust design of assembly and machining tolerance allocations. IEE Transactions, 30: 17-29.

\section{Nomenclatures}

$\bar{y} \quad$ average of observed data

$L_{8} \quad$ orthogonal array with eight numbers of experiments

$n \quad$ number of observation

$R^{2} \quad$ the coefficient of determination

$S / N \quad$ signal to noise ratio

$s_{y}{ }^{2} \quad$ variance of $y$ 